\title{
Dialectical Thinking and Exploratory Method in College Math Teaching
}

\author{
Xiao Xiaonan \\ Xiamen University Tan Kah Kee College \\ Zhangzhou Fujian China \\ xiaoxn@xujc.com
}

\begin{abstract}
This paper discusses the reform and innovation of college math teaching as well as micro thinking and macro innovation of the teaching. It explores micro dialectical thinking of modern college math teaching and macro innovation of its scientific methodology. The article establishes the integration and communication between micro thinking and macro innovation of college math teaching, which is aimed to stimulate the students' initiative in learning and creation and to promote their dialectical ability and comprehensive creativity. College math teaching paves the ground for the fostering of students into interdisciplinary talents needed by modern China.
\end{abstract}

Keywords-Math teaching; dialectical thinking; exploratory method; innovative education; comprehensive quality; interdisciplinary talent

\section{INTRODUCTION}

With the rapid development of modern science and technology, the Information Age poses a higher demand to college students' comprehensive innovation ability and brings about an arduous and urgent task to China's higher education. To accomplish this goal, how college math course teaching, which is an important basic course in the study of Science and Engineering, Financial and History and Philosophy, can closely relate to the development of modern technology has become an urgent issue for every college math teachers to solve. So are the questions of how it should constantly explore teaching approach, update teaching content, reform teaching method, cultivate and expand students' innovation thinking and ability on autonomous innovation learning, and furthermore cultivate students into comprehensive creative talents[1-3]

\section{MICROCOSMIC DIALECTICAL THINKING}

Microcosmic dialectical thinking is an interdisciplinary field that relates to both mathematic content and the process of thinking for teachers and students in college math teaching. The famous scientist Rogen Bacon has pointed out: "Mathematics is the key to the door of science." The development of science over two thousand years has repeatedly proved this argument. Especially in the 20th century, mathematics with an unprecedented speed has penetrated into almost every aspect of natural sciences, social sciences, and arts and culture. This is precisely another strong evidence. It is known to all about this relationship between mathematics and natural science. In the 20th century, math has built a strong connection with natural science, which is deeply influenced by math and interpenetrates each other. This can furthermore engender various interdisciplinary studies and form a vast frame of mathematical and physical sciences.

Also, math has formed an increasingly close tie with social science. For example, we can use mathematic method to research the language phenomenon and give a quantified and formalized description to language, which would form a mathematical linguistics discipline studying both natural language and the kind of artificial language and computer language. This approach can further tap into the potential nature of the language, solving the difficult questions in Linguistics. Another example would be that math plays an important role in the development of philosophy and logic. The concept of infinite and continuous in math has also become the object of philosophy as soon as it appeared. What's more the development of math is also related to the analytical philosophy, structuralism, and system philosophy in the 20 th century.

The most profound part in culture is the interaction between philosophy and mathematic. Mathematician B. Demollins had a good point. He said: "Without math, we can't see through the depths of philosophy; without philosophy, people can't see through mathematical depth. Whereas without them, people could not see anything." Philosophy provides a rational spirit to our civilization while math represents the innermost spirit of rationality. Thus the issues raised in math have promoted the development of philosophy.

The famous mathematician A. Kaplan asserts that "due to the advancement in the last twenty years, many important areas in social science have developed to an extent that those who know nothing about math can never catch up...We told our readers that to continue to expand the use of mathematical language in the social sciences is of great importance."

Under this circumstance, UNESCO announced "World Mathematical Year of 2000" in Rio de Janeiro, 1992. It aimed at strengthening the connection between math and society. The Declaration of Rio de Janeiro has aptly pointed out: "Pure mathematics and applied mathematics is the primary key to understanding the world and its development."

This world would need this key. Every individual who live in the modern society all need this key. 
Bertrand Russell, a famous Mathematical scientist and philosopher, said that "Not only has math owned the truth but also it owns a supreme beauty, a kind of cold and serious beauty just like the beauty of the statue..."

The beauty and authenticity of math lie in that - there are three obvious features to distinguish math from other subjects - its abstractness; its accuracy; and its extreme universal use. It can be said that math provides many distinctive ways of thinking to us. We can find many fantastic facets of math everywhere in our life and works. Mathematics is a kind of gymnastic work in our thinking, an essential tool for thinking. It has become the basic qualities of modern people.

In order to further promote students' development in all aspects; we should pay particular attention to strengthening and cultivating students' dialectical thinking, critical thinking skills, practical skills, and creative thinking ability.

In class teaching, based on the characteristics of college math teaching, we should grasp the nature of the problem and the main quality. What we should do now is to take some teaching methods that combine inspiration, discussion and guidance, which aims at solving the problem such as the basic concept students may easily confuse, difficult theories and methods, and the mistakes easily happened in problem-solving. This can strengthen the cultivation and training of the students' dialectical thinking and learning method, encourage them to learn independently, thinking independently, solving problems independently and to ask questions bravely. So students can summarize method and find out the answer by themselves. Our objective is to make this whole teaching process into a dynamic process in which students' creative thinking and innovative spirit can be developed.

To cultivate students' comprehensive dialectical thinking and innovation ability in solving practical problems on their own, teachers need to first update their concept gradually, explore their own sense of dialectical thinking and innovative consciousness constantly, follow the development of science and technology, and keep abreast of the development of the discipline. What's more, teachers need to know the most upto-date research and enrich their teaching content so that they can combine their teaching content with contemporary knowledge in economy and information age, thus to make it more rich, appealing, and interestingly[4-5].

\section{MiCROCOSMIC DIALECTICAL THINKING IS THE SOURCE OF CREATIVE EDUCATION IN COLLEGE MATH AND THAT OF LEADING AND DEVELOPING STUDENTS' CREATIVE THINKING}

Dialectical thinking is core to microcosmic thinking of college math teaching. Microcosmic dialectical thinking is the source of creative education in college math ad that of leading and developing students' creative thinking. It may seem hard to solve many of the problems in college math teaching. But as long as we use microcosmic dialectical thinking, it will shed new light on the questions to be solved.

The mode of microcosmic dialectical thinking can be found everywhere in advanced mathematics and calculus teaching.
"From infinite to finite, then from finite (approximate) to infinite (accuracy)" This microcosmic dialectical thinking is fully reflected in advanced mathematics and calculus teaching.

For instance, in the teaching of definite integral element methods, as long as we apply the micro-dialectical to discuss the issue, we can lead students to understand the concept deeply. Such as, when we divide the interval into infinite subdivisions; no matter how to split range, if the sum tends to be constant value forever. So, we can write

$$
\begin{aligned}
& I=\lim _{\lambda \rightarrow 0} \sum_{i=1}^{n} f\left(\xi_{i}\right)_{X_{i}}=\int_{a}^{b} f(x) d x, \text { where } \\
& \lambda=\max \left\{\Delta x_{1}, \Delta x_{2}, \ldots, \Delta x_{n}\right\}
\end{aligned}
$$

In the college statistic teaching, it is also filled with microdialectical thinking. Due to its different way of thinking from advanced mathematics, many students may feel quite challenging when first studying the statistical methods. However, if teachers can use the micro-dialectical thinking to discuss and analysis the related questions and difficulties when dealing with these abstract and complex problems in statistical method teaching, it can open students' eyes and easily solve the problem.

For example, in the progress of dealing with the hypothesis and difficult teaching points, since we have aptly used the dialectical thinking to discuss the connection and difference between interval estimation of parameters and hypothesis testing, students can deeply understand the inter-influence and communication among the interval estimation and hypothesis testing in statistical inference. Moreover, it would cultivate and open up students' comprehensive abilities in innovative dialectical thinking and independent innovation learning.

Not only should we explain the basic concept and conduct the basic training to our students but also we need to care more to use the dialectical thinking flexibly. What we need to do is to identify some typical, confusing and ambivalent questions and analyze these problems deeply so that students can open up their mind and learn the basic method to analyze problems dialectically. For example, to let every student learn well in mathematical statistics, we need to analyze its "difficult" but "easy" feature deeply and dialectically in class teaching: "difficult" because of the restriction of the hours and foundations. Some related theories from this part of content are not easy to be explained in detail; hence the students cannot grasp its original implications. On the other hand, it is "easy" for that as long as teachers pay attention to their teaching methods and spell out the key issues; it is easy for us to learn the mathematical statistics. Formula and method of mathematical statistics tend to have certain rules we could follow. As long as we follow the required steps, we can draw the right conclusion and solve the problem. Specifically, "hard" because it mainly focuses on leading-outnormal distribution, $\chi^{2}$ distribution, $t$ distribution and $F$ distribution; "easy" because what we use is not the proof of this reduction but the application of the related conclusion and relevant calculation (mainly looking up the table and calculating). However, to look up the table and calculate is not really 
difficult. So we can transfer the work naturally from "difficult" to "easy" and students can accept it easily.

Our practice has proved that in college math teaching, using dialectical thinking flexibly and skillfully in teaching can play an important role in developing students' creative thinking, cultivating students' comprehensive ability, and improve teaching quality. These methods are really popular among the students. In this regard, we will continue to work hard to improve our college mathematics teaching as fast as possible, deepen our teaching reform, and enhance students' comprehensive mathematics capabilities and make our longdue contributions.

\section{CONSTANTLY SEEK INNOVATION, AND ESTABLISH A SCIENTIFIC SYSTEM OF COLLEGE MATHEMATICS TEACHING}

Combine the practical reform in college mathematics teaching, constantly seek innovation, and establish a scientific system of college mathematics teaching. The famous scientist Yang Zhengning has said: "studying should not be the ultimate objective for learning; it should be a means to create new knowledge and new system." This should indeed attract our great attention. According to the characteristics of university mathematics learning, we should pay special attention to guide student to think of and analyze questions dialectically and from various angles. We need to make attempt to inspire students to identify and summarize the theoretic system and thinking mode essential to university mathematics, expand the horizon, and apply it adroitly to solve the practical issues. We should also encourage students to use college math knowledge deeply and to participate the extracurricular scientific and technological activities actively. Therefore they can select some projects of their own interest to conduct research, which they would have sufficient room for independent thinking and self-study. This way it would further to develop the students' subjective initiative in the teaching activities[6-7].

In order to build our college's math curriculum into a true high quality course across all the universities nationwide, from a macroscopic point of view we should innovate and deepen the college mathematics teaching reform. We need to constantly update teaching content and improve our teaching methods. A series of scientific and multi-dimensional college math teaching system, which is open, interactive, artistic, and research/guiding/discussion/debate-oriented, should be built to break through the traditional, constrained classroom teaching method. The new measures can further stimulate students' enthusiasm in motivated learning, provide a strong foundation to, and further improve the students' comprehensive quality and innovation ability.

To reform college math education is to fully use the above modern teaching methods and multimedia teaching tools to stimulate students' comprehensive innovation awareness and innovation ability. We need to reinforce the college mathematics teaching reform and build six new grounds: groundbreakings, innovation, universality, objectivity, rigorousness and applicability. We should combine the newest knowledge with the developing trends of the discipline organically in our teaching. This can constantly open up students' horizons, expanding students' knowledge and comprehensively cultivating students' innovation quality and the ability of analysis and problem-solving [8]

\section{THE ULTIMATE GOAL OF UNIVERSITY MATHEMATICS INNOVATION EDUCATION}

Theory should be closely linked to reality. The ultimate goal of university mathematics innovation education is to improve students' comprehensive ability of analysis and application and to make students into innovation, comprehensive talents which echoes the call of our nation; development. The extensive application of mathematics has shown that "the 21 century is an information age whereas the information age is the mathematics era." Therefore, this requires the university mathematics education must closely combine theory with reality and continue to reform and innovate. College math teaching should adapt to the development of information society and meet its new demand. Through college math innovation education, we can cultivate more innovative and comprehensive talents for our country.

In college math teaching, to insist combining theory and reality is to highlight the applicability of college mathematics learning, reinforce the comprehensive training of students in teaching practice, emphasize the integration of knowledge and its application, broaden the students' horizon, and underscore the innovation and practicability in college teaching. Only in this way, the university mathematics teaching will be heartily welcomed by students and in line with our school's teaching practice, thus lay a solid foundation for the students to become the pillars of the country.

\section{CONCLUSION}

At present, in college, the teaching reform is deepened and pattern of cultivation talents is explored. It has been a key subject for all the college teachers to size opportunity to strengthen comprehensive quality of students and educate more compound and applied creative talents in educational practice. It is a glorious and arduous task that we must explore and practice, change educational ideas speedily, deepen the education reform continually, create talent development continually and teaching model, fight for educating more comprehensive and creative talents for economic development for our country in $21^{\text {st }}$ century.

\section{REFERENCES}

[1] Zhang Zhonghua. Modern Teaching Methodology [M]. Harbin: Heilongjiang People's Publishing House, 2009.

[2] Zou Xiaodong. Innovation in Science and Engineering Education: Strategies, Patterns and Countermeasures [M]. Beijing Science Press, 2010.

[3] Meng Xianzhi. A Research of Disciplinary Theory and Practice on the Construction of New Private College [M]. Beijing: Chinese Academy of Agricultural Science and Technology Press, 2009.

[4] Gao Youhua. A Study on the Theory of New Higher Education Courses [M]. Zhenjiang: Jiangsu University Press, 2009. 
[5] Ministry of Education. Observations with Regard to Further Deepening the Reform of Undergraduate Education, and Comprehensively Improve the Quality of Education[R].

[6] Li Wuyi, Xing Yongfu. Frontier Research in China Education [M]. Taiyua: Shanxi Education Press, 2004.
[7] Tang Zhixiang. Jiang Zemin's Educational Innovation Studies [M]. Changsha; Hunan People's Publishing House, 2003.

[8] Zhu Qingshi. Reform and Development of Higher Education in the 21st Century [M]. Beijing: Higher Education Press, 2002. 